Cuadernos de Historia Contemporánea

ISSN: 0214-400X

https://dx.doi.org/10.5209/chco.78174

\title{
Nación y masculinidades: reflexiones desde la historia ${ }^{1}$
}

\author{
Xavier Andreu-Miralles ${ }^{2}$
}

Recibido: 22 de julio de 2020 / Aceptado: 23 de julio de 2021

Resumen. El texto analiza la relación entre nación y masculinidad en el mundo contemporáneo a partir del diálogo con una serie de debates teóricos recientes. En primer lugar, reflexiona sobre la conexión entre nación, masculinidad y "modernidad". Seguidamente, se interroga sobre el concepto de "masculinidad nacional". En tercer lugar, plantea la necesidad de rehuir una interpretación rígida de la relación entre ambas categorías. Finalmente, el texto concluye que para estudiar de forma compleja la relación que se establece en el mundo contemporáneo entre la nación y la masculinidad es necesario introducir la perspectiva histórica y atender a la acción de los sujetos históricos.

Palabras clave: Nacionalismo; masculinidades; modernidad; masculinidad nacional; historia.

\section{[en] Nation and Masculinities. Reflections from History}

\begin{abstract}
This article deals with the relationship between nation and masculinity in modern history. It draws on some recent theorical debates. Firstly, it reflects on the connection between nation, masculinity and "modernity". Then, it examines the concept of "national masculinity". Third, the article argues for avoiding a rigid understanding of the relationship between both categories. Finally, it concludes stressing the importance of introducing the historical perspective and attending to the agency of historical subjects.
\end{abstract}

Keywords: Nationalism; masculinities; modernity; national masculinity; history.

Sumario. Introducción. 1. La nación y la "masculinidad moderna". 2. Masculinidades nacionales. 3. Nación y masculinidad: una relación inestable. 4. A modo de conclusión: la historia y la vuelta del sujeto. 5. Referencias bibliográficas.

Cómo citar: Andreu-Miralles, X. (2021). Nación y masculinidades: reflexiones desde la historia. Cuadernos de Historia Contemporánea, Vol. 43, 121-143.

\section{Introducción}

En los últimos años, el estudio de las masculinidades ha permitido ampliar una historia de género que, aunque desde el principio se planteó y propuso como relacional, ha tendido a centrarse en los discursos de la feminidad o en las experiencias de las mujeres. La historia de las masculinidades estudia la construcción histórica de lo

\footnotetext{
$1 \quad$ El autor participa de los proyectos "Narrar el gènere i la nació: Espanya, 1843-1898” (GV2019/111) y "Derechas y nación en época contemporánea. Una perspectiva transnacional” (PGC2018-099956-B-I00).

2 Universitat de València

E-mail: xavier.andreu@uv.es
} 
"masculino" y sus consecuencias para la construcción de las subjetividades y las relaciones de poder". Propone desestabilizar la categoría "hombre", subrayando su carácter histórico y no esencial, y visibilizando la dimensión de género de un sujeto moderno habitualmente conceptualizado como abstracto y neutro ${ }^{4}$. A su vez, cuestiona la universalidad de este sujeto y subraya la pluralidad de masculinidades existentes en contextos históricos específicos, así como las relaciones jerárquicas que se establecen entre ellas 5 .

La masculinidad no posee ningún significado intrínseco o fundacional, ni tiene ningún anclaje biológico. Como señaló Sinha, la construcción de la masculinidad colonial "disrupts any stable equation between gender identity and sex difference: it demonstrates that masculinity had as much to do with racial, class, religious, and national differences as with sex difference" . Por ello, no podemos limitar la historia de la masculinidad al estudio de los hombres - como no podemos reducir la feminidad al de las mujeres ${ }^{7}$. Como han propuesto diversas especialistas, debería avanzarse hacia una historia de la masculinidad sin hombres; es decir, sin asumir que, en última instancia, el significado o la propia existencia de esta categoría procede de la relación que mantiene con unos determinados cuerpos sexuados ${ }^{8}$. Esto implica analizar las diversas categorías que se cruzan y dotan de significado a lo "masculino" en cada contexto histórico concreto 9 . En primer lugar, la de feminidad, por supuesto, pero también la raza, la etnicidad, la sexualidad, la religión, la clase, etc. Más que como un opuesto, la feminidad funciona como uno más de los "suplementos" que permiten enunciar y articular qué significa ser "masculino" en cada momento ${ }^{10}$.

En este texto me ocuparé principalmente de la relación que se establece en el mundo contemporáneo entre la masculinidad y una de estas categorías, la nación, aunque sin perder de vista que se conjuga siempre simultáneamente y de formas

3 Una introducción a la historia de la masculinidad y a algunos de sus conceptos y preguntas fundamentales en Aresti, Nerea: "La historia de género y el estudio de las masculinidades. Reflexiones sobre conceptos y métodos", en Henar Gallego (ed.): Feminidades y masculinidades en la historiografía de género, Granada, Comares, 2018, pp. 173-194. Un balance reciente sobre cómo se ha ido abriendo camino esta perspectiva en el ámbito historiográfico español en Aresti, Nerea: "La historia de las masculinidades, la otra cara de la historia de género", Ayer, 117 (2000), pp. 248-265.

4 Blom, Ida, Hagemann, Karen y Hall, Catherine (eds.): Gendered Nations. Nationalisms and Gender Order in the Long Nineteenth Century, Oxford, Berg, 2000; Dudink, Stefan, Hagemann, Karen y Clark, Anna (eds.): Representing Citizenship. Male Citizenship in Modern Western Culture, Nueva York, Palgrave Macmillan, 2007.

5 Connell, Raewyn W.: Masculinities, Cambridge, Polity Press, 1995; Sinha, Mrinalini: Colonial Masculinity: The 'Manly Englishman' and the 'Effeminate Bengali' in the Late Nineteenth Century, Manchester, Manchester University Press, 1995.

6 Sinha, Mrinalini: Colonial Masculinity..., p. 182.

7 Martin, Patricia Y.: "Why Can't Be a Man More Like a Woman? Reflections on Connell's Masculinities", Gender \& Society, 12-4 (1998), pp. 472-474.

$8 \quad$ Halberstam, Judith: Female Masculinity, Durham, Duke University Press, 1998.

9 Sinha, Mrinalini: "Giving Masculinity a History: Some Contributions from the Historiography of Colonial India", Gender \& History, 11-3 (1999), pp. 445-460.

10 Tosh, John: "Hegemonic Masculinity and the History of Gender", en Stefan Dudink, Karen Hagemann y John Tosh (eds.): Masculinity in Politics and War. Gendering Modern History, Manchester, Manchester University Press, 2004, pp. 41-58; Reeser, Todd: Masculinities in Theory. An Introduction, Oxford, Willey-Blackwell, 2010, pp. 66-71. De todos modos, Mimi Schippers subraya que cualquier conceptualización de la masculinidad se define por cómo se articula en relación complementaria y jerárquica con otras feminidades, algunos de cuyos rasgos son transferidos a estas Otras masculinidades para naturalizar las relaciones de dominación que se establecen entre ellas; Schippers, Mimi: "Recovering the Feminine Other: Masculinity, Femininity, and Gender Hegemony", Theory and Society, 36-1 (2007), pp. 85-102. 
variables con el resto de ellas ${ }^{11}$. El artículo establece un diálogo con una serie de debates teóricos que nos permiten hacer más complejo el estudio del vínculo entre la nación y las masculinidades contemporáneas. Parte de las principales referencias internacionales que se han ocupado de esta relación, si bien repasa especialmente algunos trabajos que desde la historiografía española han empezado a abordar esta cuestión en los últimos años. En primer lugar, reflexiona sobre la conexión de la nación y la masculinidad con la "modernidad" y sus relatos. Seguidamente, se interroga sobre la utilidad y los peligros de un concepto como el de "masculinidad nacional". Por último, plantea la necesidad de rehuir una interpretación de la relación entre nación y masculinidad construida sobre la noción de una correspondencia entre categorías estables. El texto concluye que para estudiar de forma compleja dicha relación es necesario introducir la perspectiva histórica y atender a la acción de los sujetos históricos.

\section{La nación y la "masculinidad moderna"}

En la década de 1990, tanto Masculinities de Raewyn Connel como The Image of Man de George L. Mosse subrayaron el carácter peculiar de las masculinidades contemporáneas y su estrecha vinculación con el nacionalismo. Connell sitúa a este último como uno de los ingredientes fundamentales de la masculinidad hegemónica moderna, fruto, en el mundo occidental, del avance progresivo de la secularización, el racionalismo, el individualismo, la industrialización y la institucionalización del poder del Estado. Aunque ha resultado útil para desbrozar el camino, su propuesta, como han señalado diversos autores, resulta teleológica y adolece de los matices y complejidades que aportaría un planteamiento más atento a la evidencia histórica. Estos autores advierten del peligro que encierra una interpretación que parece entender la historia de la masculinidad como el paso sucesivo y lineal, como en bloques o estadios de desarrollo, de un modelo de masculinidad a otro, sin atender a la larga duración, a las continuidades o a las pervivencias ${ }^{12}$. Desde el flanco contrario, John Tosh arguye que la ausencia de perspectiva histórica impide a Connell tener en cuenta que la masculinidad hegemónica puede transformarse rápidamente en contextos revolucionarios, como habría ocurrido en el mundo occidental en las primeras décadas del siglo XIX ${ }^{13}$.

La otra gran propuesta teórica sobre los orígenes de la "masculinidad moderna", la de George L. Mosse, se alimenta más de la historia y le confiere aún mayor importancia al nacionalismo. Según Mosse, en el contexto de las guerras napoleónicas, el nacionalismo decimonónico asumió el modelo bélico y militarista del ciudadanosoldado revolucionario y lo mezcló, de formas diversas, con los nuevos valores de la respetabilidad de las clases medias ascendentes. En una sociedad marcada por

11 Sobre la relación más amplia entre nación y género, Andreu, Xavier: "El género de las naciones. Un balance y cuatro propuestas", Ayer, 106 (2017), pp. 21-46.

12 Harvey, Karen y Shepard, Alexandra: "What Have Historians Done with Masculinity? Reflections on Five Centuries of British History, circa 1500-1950", Journal of British Studies, 44 (2005), pp. 274-280; French, Henry y Rothery, Mark: "Hegemonic Masculinities? Assessing Change and Processes of Change in Elite Masculinity, 1700-1900", en John H. Arnold y Sean Grady (eds.): What is Masculinity? Historical Dynamics from Antiquity to the Contemporary World, Basingstoke, Palgrave Macmillan, 2013, pp. 139-166.

13 Tosh, John: "Hegemonic Masculinity...". 
el cambio económico y la transformación social, la nueva masculinidad respetable permitió combinar mudanza y estabilidad en el mundo postrevolucionario; cerrar la revolución sin detener la modernización. La fusión (variable) de estos elementos habría dado lugar a una masculinidad moderna cuyos rasgos distintivos se habrían fijado esencialmente en las primeras décadas del siglo $\mathrm{XIX}^{14}$.

La propuesta de Mosse plantea también algunos problemas. En primer lugar, su "masculinidad moderna" resulta excesivamente estable, universal y homogénea, quizá porque su análisis descansa sobre la noción de estereotipo de género, tendencialmente estabilizadora en sí misma. En las últimas décadas, numerosas historiadoras e historiadores del género han demostrado el carácter inestable, cambiante y heterogéneo de las masculinidades contemporáneas. Más que el equilibrio, parece ser la "crisis" el estado natural de unas subjetividades masculinas que necesitan estar continuamente afirmándose. Asimismo, más que "un” único modelo prevalente, como ya subrayó Connell, la norma es la multiplicidad de masculinidades en cualquier lugar y momento histórico ${ }^{15}$.

Igual de problemático resulta que tanto Connell como Mosse vinculen la aparición de la "masculinidad moderna" y su estrecho vínculo con el nacionalismo a la llegada de una "modernidad" que, en última instancia, acaba identificándose con una serie de grandes transformaciones estructurales en las que los sujetos históricos parecen tomar parte sólo de manera subsidiaria. Tanto el nacionalismo como la "masculinidad moderna" serían la respuesta a un mundo transformado por la revolución industrial y el ascenso de la burguesía - protagonista, en última instancia, de las transformaciones políticas del periodo. Este planteamiento lleva implícita la idea de que sólo en aquellos lugares en los que esas transformaciones de fondo se hubieran producido sería posible (por necesaria) la aparición tanto del nacionalismo como del nuevo ideal de masculinidad. En definitiva, ambos planteamientos descansan en presupuestos materialistas para los que el estudio del nacionalismo y de la masculinidad moderna en sí mismos, o de la estrecha relación que se establece entre ambos, pueden acabar resultando secundarios.

Diversos autores han puesto de manifiesto la relevancia de los procesos revolucionarios liberales y de las guerras napoleónicas en la fijación de una nueva relación entre nación y masculinidad, ahondando en lo ya apuntado por Mosse ${ }^{16}$. Sus

14 Mosse, George L.: La imagen del hombre. La creación de la moderna masculinidad, Madrid, Talasa, 2001. También, Mosse, George L.: Nationalism and Sexuality. Respectability and Abnormal Sexuality in Modern Europe, Nueva York, Howard Fretig, 1985.

15 Kimmel, Michael: Manhood in America. A Cultural History, Nueva York, Oxford University Press, 1996; Tosh, John: A Man's Place. Masculinity and the Middle-Class Home in Victorian England, Londres, Yale University Press, 1999; Dudink, Stefan, Hagemann, Karen y Clark, Anna (eds.): Representing Citizenship...; Forth, Christopher E. y Taithe, Bertrand (eds.): French Masculinities: History, Culture and Politics, Basingstoke, Palgrave Macmillan, 2007; Dudink, Stefan, Hagemann, Karen y Tosh, John (eds.): Masculinities in Politics and War...; Sohn, Anne-Marie: “Sois un Homme!" La construction de la masculinité au XIXe siècle, París, Seuil, 2009; Peluffo, Anna y Sánchez Prado, Ignacio M. (eds): Entre hombres: masculinidades del siglo XIX en América Latina, Madrid y Frankfurt, Iberoamericana-Vervuert, 2010; Corbin, Alain (dir.): Histoire de la virilité 2. Le triomphe de la virilité. Le XIXe siècle, París, Seuil, 2011.

16 Colley, Linda: Britons. Forging the Nation 1707-1837, Londres, Yale University Press, 1992, pp. 283-319; Hagemann, Karen: “Of 'Manly Valor' and 'German Honor': Nation, War, and Masculinity in the Age of the Prussian Uprising against Napoleon”, Central European Review, 30-2 (1997), pp. 187-220; Banti, Alberto M.: L'onore della nazione. Identità sessuali e violenza nel nazionalismo europeo dal XVIII secolo alla Grande Guerra, Turín, Einaudi, 2005; Hagemann, Karen, Mettele, Gisela y Rendall, Jane (eds.): Gender, War and Politics. Transatlantic Perpsectives, 1775-1830, Londres, Palgrave Macmillan, 2010. Para el caso español, Andreu, 
trabajos, no obstante, subrayan la autonomía de lo político y de lo cultural en unos cambios que tuvieron lugar en todo el mundo occidental más allá de las dispares realidades sociales y económicas de cada uno de ellos. Stefan Dudink sugiere incluso que el secreto de la particular relación que se estableció en el mundo contemporáneo entre nación y masculinidad se debió a que se reforzaron la una a la otra al atribuirse mutuamente el poder de autodeterminarse ${ }^{17}$. Asimismo, a partir sobre todo de trabajos procedentes de la historia de la ciencia inspirados en la obra de Thomas Laqueur, algunos autores señalan que la nueva relación que se estableció en aquellas décadas entre género, raza y nación, más que a grandes mudanzas socioeconómicas, fue debida a un cambio radical en la manera de entender el yo y la identidad. En aquellas décadas, ambas categorías empezaron a pensarse como naturales e inmóviles, y como fijadas cada vez más en el cuerpo ${ }^{18}$.

En todo caso, y aun reconociendo la fractura que supuso este periodo revolucionario, estos estudios han planteado también la necesidad de establecer las líneas de continuidad existentes entre determinados ideales de masculinidad patriótica presentes ya en siglos previos y los propios de la era del nacionalismo moderno ${ }^{19}$. Judith Banister, por ejemplo, ha demostrado que en el siglo XVIII el ideal del hombre polite no fue quizás tan hegemónico como se presumía, ni siquiera en Inglaterra. Durante todo el siglo fue contestado por otros modelos de masculinidad que, a finales de la centuria y en el marco de las guerras contra la Francia revolucionaria, acabarían asociándose con la defensa de un "carácter nacional" amenazado ${ }^{20}$. Asimismo, diversos trabajos han matizado la radicalidad del cambio de paradigma sexual propuesta por Laqueur, subrayando tanto sus precedentes en siglos anteriores como la persistencia de modelos alternativos al de la complementariedad de los sexos en el siglo XVIII y a lo largo de todo el XIX ${ }^{21}$.

A pesar de todos estos matices, existe un cierto consenso sobre el vínculo especial que se habría producido entre el nacionalismo y determinados ideales de masculinidad en el mundo contemporáneo. Ahora bien, en cualquier caso, ese vínculo no debería entenderse como preceptivo, ni partir de una definición previa y sin reservas de lo que significa ser "moderno". Entendida como una serie de indicadores supuestamente inocuos y objetivos de un proceso de transformación universal por el que transitan todas las sociedades en su camino hacia el futuro, el concepto de "moderni-

Xavier: "A Fatherland of Free Men: Virility and 'Frailty' in Spanish Liberalism (1808-1814)", Gender and History, 33-3 (2021).

17 Dudink, Stefan: "Multipurpose Masculinities. Gender and Power in Low Countries Histories of Masculinity", BMGN-Low Countries Historical Review, 127-1 (2012), pp. 5-18.

18 Hitchcock, Tim y Cohen, Michèle (eds.): English Masculinities, 1660-1800, Londres, Longman, 1999; Wahrman, Dror: The Making of the Modern Self. Identity and Culture in Eighteenth-Century England, Londres, Yale University Press, 2006; Dorlin, Elsa: La matrice de la race. Généalogie sexuelle et coloniale de la Nation française, París, La Découverte, 2009; Corbin, Alain: "La virilité reconsiderée au prisme du naturalisme", en Alain Corbin (dir.), Histoire de la virilité..., pp. 15-30.

19 Por ejemplo, los ideales viriles y virtuosos de la tradición republicana; Pocock, J. G. A.: El momento maquiavélico: el pensamiento político florentino y la tradición republicana atlántica, Madrid, Tecnos, 2002; Dudink, Stefan: "Masculinity, Effeminacy, Time: Conceptual Change in the Dutch Age of Democratic Revolutions", en Stefan Dudink, Karen Hagemann y John Tosh (eds.): Masculinities in Politics and War..., pp. 77-95.

20 Banister, Judith: Masculinity, Militarism and Eighteenth-Century Culture, 1689-1815, Cambridge, Cambridge University Press, 2018; Cohen, Michèle: Fashioning Masculinity: National Identity and Language in the Eighteenth Century, Londres, Routledge, 2002.

${ }^{21}$ Harvey, Karen: "The Century of Sex? Gender, Bodies, and Sexuality in the Long Eighteenth Century", The Historical Journal, 45-4 (2002), pp. 899-916. 
dad" tiende a encerrar una visión normativa del desarrollo de las sociedades que sanciona o legitima las relaciones de poder que se establecen entre ellas ${ }^{22}$. Resulta más productivo, probablemente, entenderla como un proyecto o como un relato, siempre en disputa $-\mathrm{y}$ de indudables consecuencias históricas. Para el caso que nos ocupa, más que analizar cómo se configura el "hombre moderno", lo que resulta interesante analizar es quizás cómo la noción de "modernidad" participa en la definición y la práctica de las masculinidades contemporáneas ${ }^{23}$.

En un tiempo en el que las naciones se imaginan históricamente, la "modernidad" de los sujetos que las integran se convierte en una vara de medir su estado de civilización y de progreso -así como en un objetivo a alcanzar mediante su reforma o transformación. Este fenómeno ha sido estudiado en el caso de las mujeres: desde la Ilustración, su conducta y moralidad se convirtieron en indicadores de la "modernidad" de las diversas sociedades del globo ${ }^{24}$. En el siglo XIX esta relación entre mujeres, nación y modernidad se consolidó. Lo hizo incluso en aquellas sociedades excluidas del relato hegemónico del progreso que se vieron obligadas a negociar y reformular esos conceptos para preservar su singularidad cultural al tiempo que afirmaban su compatibilidad con el mundo moderno ${ }^{25}$.

Ahora bien, este proceso afectó igualmente a los discursos sobre la masculinidad, como ya señaló el propio Mosse. El debate sobre la modernidad de la nación se centró también a lo largo de la época contemporánea en los rasgos y las conductas de los hombres que las integraban. Los ejes civilización-barbarie o modernidad-atraso fueron fundamentales a la hora de fijar y prescribir los ideales de masculinidad en este periodo. En el caso español, las sospechas sobre las carencias en su civilización y, particularmente, sobre la barbarie de sus habitantes, compartidas en mayor o menor grado por propios y por extraños, acentuadas tras el "Desastre del 98", se tradujeron en múltiples propuestas modernizadoras que pasaban por la reeducación nacional de los hombres españoles; en empresas imperiales que buscaban afirmar su virilidad y su pertenencia al mundo civilizado; o en nacionalismos alternativos que se reivindicaban en el contraste entre la modernidad respetable de sus varones y el rudo primitivismo del resto de los españoles ${ }^{26}$.

22 Chakrabarty, Dipesh: Provincializing Europe. Postcolonial Thought and Historical Difference, Princeton, Princeton University Press, 2008.

23 Harvey, Karen y Shepard, Alexandra: "What Have Historians Done...".

24 Bolufer, Mónica: "Civilización, costumbres y política en la literatura de viajes a España en el siglo XVIII", Estudis: Revista de historia moderna, 29 (2003), pp. 255-300; Maleĉková, Jitka: "Women in Perceptions of Uneven Development”, en Miroslav Hroch y Luda Klusáková (eds.): Criteria and Indicators of Backwardness. Essays on Uneven Development in European History, Praga, Variant, 1996, pp. 143-156.

25 Chatterjee, Partha: The Nation and Its Fragments: Colonial and Postcolonial Histories, Princeton, Princeton University Press, 1993

26 La bibliografía sobre estas cuestiones es ya extensa. Véanse, especialmente, Aresti, Nerea: "A la nación por la masculinidad. Una mirada de género a la crisis del 98", en Mary Nash (ed.): Feminidades y masculinidades. Arquetipos y prácticas de género, Madrid, Alianza Editorial, 2014, pp. 47-74; Aresti, Nerea, Peters, Karin y Brühne, Julia (coords.): ¿La España invertebrada? Masculinidad y nación a comienzos del siglo XX, Granada, Comares, 2016; Aresti, Nerea y Martykánová, Darina (coords.): Masculinidades, nación y civilización en la España contemporánea, Cuadernos de Historia Contemporánea, 39 (2017); Zabalgoitia, Mauricio (ed.): Hombres en peligro: género, nación e imperio en la España de cambio de siglo (XIX-XX), Madrid, Iberoamericana-Vervuert, 2017; Torres, Gemma: La virilitat d'Espanya a l'África. Nació i masculinitat al colonialisme al Marroc (1880-1927), Catarroja, Afers, 2020. Planteamientos similares, aunque para periodos y problemáticas anteriores, en Andreu, Xavier: El descubrimiento de España. Mito romántico e identidad nacional, Barcelona, Taurus, 2016, pp. 213-235; Sierra, María: "Hombres arcaicos en tiempos modernos. La construcción romántica de la masculinidad gitana", Historia social, 93 (2019), pp. 51-65. 
Estos trabajos sobre la crisis de masculinidad española del fin de siglo y sus consecuencias ponen de manifiesto, asimismo, la relación variable, histórica y diversa que se establece en el mundo contemporáneo entre nación, modernidad y masculinidad. Una relación tan variable, histórica y diversa como lo son cada uno de dichos conceptos y que, por ejemplo, no siempre se ha construido sobre la exclusión de lo "femenino", como ha estudiado José Javier Díaz Freire a propósito de las propuestas regeneracionistas de Miguel de Unamuno ${ }^{27}$. En la Argentina de inicios del siglo XIX, por poner otro ejemplo en este mismo sentido, la voluntad de presentarse como una nación moderna y alejada de la barbarie "premoderna" (identificada con América y con el gobierno de Juan Manuel de Rosas), llevó a Domingo Faustino Sarmiento y a la Generación de 1837 a propugnar una masculinidad europea, civilizada y parcialmente "femenina", como la más deseable para la nación argentina ${ }^{28}$.

\section{Masculinidades nacionales}

Otro concepto relevante para lo que nos ocupa es el de "masculinidad nacional", es decir, el tipo de masculinidad que es considerado el propio de la nación. La convicción de poseer un determinado "carácter nacional" compartido, propio tanto de hombres como de mujeres, aunque se encarne en ellos de manera diferenciada, es uno de los elementos fundamentales a través de los cuales se ha sostenido la ficción nacional en la época contemporánea ${ }^{29}$. Entendido en estos términos, propios del discurso nacionalista, el concepto de "masculinidad nacional" resulta, obviamente, poco útil.

Es igualmente problemática por motivos similares la identificación a menudo ahistórica que, sobre todo desde la antropología, se ha hecho entre determinados modelos de masculinidad y algunas "culturas" determinadas. Un caso paradigmático es el de la cuenca mediterránea. En trabajos clásicos como el de Julian Pitt-Rivers o en otros que incorporan más matices, aunque resulten igualmente discutibles como los de David Gilmore, las naciones mediterráneas y las latinas, como descendientes suyas, parecen condenadas a reproducir unos ideales de masculinidad dominados por el honor o la violencia cuasi atemporales, en tanto que enraizados en una tradición cultural que se hace remontar a la tradición homérica ${ }^{30}$.

27 Díaz Freire, José Javier: "Miguel de Unamuno: la feminización de la masculinidad moderna", Cuadernos de Historia Contemporánea, 39 (2017), pp. 39-58.

28 Alicia Jagoe, Eva-Lynn: “Asociaciones afectivas: literatura y política en la Argentina del siglo XIX o "cómo ser europeo en América”, en Anna Peluffo e Ignacio M. Sánchez Prado (eds.): Entre hombres..., pp. 109-122. En el caso español y en este mismo periodo, la retórica viril y patriótica del radicalismo no estaba reñida con la emoción o el sentimentalismo; Andreu, Xavier: "Tambores de guerra y lágrimas de emoción. Nación y masculinidad en el primer republicanismo", en Aurora Bosch e Ismael Saz (coords.): Izquierdas y derechas ante el espejo: culturas políticas en conflicto, Valencia, Tirant lo Blanch, 2016, pp. 91-118. Asimismo, Darina Martykánová y Víctor M. Núñez-García han señalado la dimensión emocional de la masculinidad patriótica de los hombres de ciencia de la España decimonónica; Martykánová, Darina y Víctor M. Núñez-García: “Ciencia, patria y honor: los médicos e ingenieros y la masculinidad romántica en España (1820-1860)”, Stvdia Histórica. Historia contemporánea, 38 (2020), pp. 45-75.

29 Leerssen, Joep: El pensament nacional a Europa. Una història cultural, Catarroja, Afers, 2019.

30 Pitt-Rivers, Julian: Antropología del honor o política de los sexos: ensayos de antropología mediterránea, Barcelona, Crítica, 1979; Gilmore, David: Manhood in the Making. Cultural Concepts of Masculinity, Londres, Yale University Press, 1990. Una crítica a estas aproximaciones en Herzfeld, Michael: Anthropology Through the Looking-Glass. Critical Ethnography in the Margins of Europe, Cambridge, Cambridge University Press, 1987. 
Introducir la perspectiva histórica resulta imprescindible para evitar estas lecturas: para analizar las continuidades en las formas de entender la masculinidad en una sociedad determinada a lo largo del tiempo, pero también las rupturas y transformaciones, y sin caer en esencialismos. Estudios dedicados a diversos países latinoamericanos discuten, por ejemplo, que en la mayor parte del siglo XIX el ideal de masculinidad nacional prevalente en ellos se vinculara con la homofobia o la agresividad, rasgos habitualmente asociados con el llamado "macho latino"31. En México, por ejemplo, solo a finales del siglo XIX, durante el Porfiriato (1876-1911) y con la llegada de las ideas positivistas, racistas y degeneracionistas, así como del nuevo discurso médico sobre la homosexualidad, empezó a cuestionarse un ideal de masculinidad nacional que en las décadas anteriores aceptaba sin problemas el afecto, la sentimentalidad, el refinamiento e incluso el trato homoerótico entre los hombres ${ }^{32}$.

Tampoco podemos analizar la "masculinidad nacional" como el tipo de masculinidad existente en un país determinado cuya conformación parece el resultado exclusivo de dinámicas internas. Este "nacionalismo metodológico", al utilizar el marco nacional como unidad acrítica de análisis, puede acabar naturalizando y reproduciendo, aun sin buscarlo, ese marco nacional ${ }^{33}$. Por supuesto, no se trata de eliminar la "nación" como categoría de análisis o espacio de referencia fundamental. En el mundo contemporáneo, los discursos de género y de nación se han articulado principalmente en esferas públicas nacionales y en relación con las políticas soberanas de los modernos Estados-nación $^{34}$. Más que despejar la nación, una categoría trascendental para entender el mundo contemporáneo, de lo que se trata es de incorporar a la ecuación una perspectiva que tenga en cuenta la relevancia que tienen los procesos transnacionales en el propio desarrollo de las formas de entender la nación, la masculinidad y las relaciones que se establecen entre ellas ${ }^{35}$. Al fin y al cabo, los ideales de masculinidad se configuran siempre en la interacción de dinámicas locales, regionales y globales ${ }^{36}$.

De hecho, la dimensión transnacional de las "masculinidades nacionales" está inscrita en su propia naturaleza. El pensamiento nacional es inherentemente comparativo. Toda nación se imagina en un mundo de naciones a través de las cuales define su propia particularidad y diferencia ${ }^{37}$. La "masculinidad nacional" tampoco puede

31 Peluffo, Anna y Sánchez Prado, Ignacio M. (eds.): Entre hombres... Un cuestionamiento en estos términos históricos de la identificación de la masculinidad española con la figura del macho heterosexual en Armengol, Josep M. (ed.): Queering Iberia. Iberian Masculinities at the Margins, Nueva York, Peter Lang, 2012. No obstante, al situar los modelos alternativos a esa masculinidad española en la periferia peninsular, más que discutir per se la identificación esencialista, puede acabar aceptándose como buena para una parte de la península (la de matriz castellana).

32 Irwin, Robert McKee: Mexican Masculinities, Minneapolis, University of Minnesota Press, 2003.

33 Sobre el nacionalismo metodológico, Wimmer, Andres y Schiller, Nina Glick: "Methodological Nationalism and Beyond: Nation-State Building, Migration and the Social Sciences", Global Networks, 2-4 (2002), pp. 301-334.

34 Eley, Geoff: “Culture, Nation and Gender”, en Ida Blom, Karen Hagemann y Catherine Hall (eds.): Gendering Nations..., pp. 27-40.

35 Horn, Maja: Masculinity After Trujillo: The Politics of Gender in Dominican Literature, Gainesville, University Press of Florida, 2014. Buenos ejemplos para el caso español son la influencia de las migraciones o del turismo en la reformulación de las masculinidades nacionales, González-Allende, Iker: Hombres en movimiento. Masculinidades españolas en los exilios y migraciones, 1939-1999, West Lafayette, Purdue University Press, 2018; Nash, Mary: "Masculinidades vacacionales y veraniegas: el Rodríguez y el donjuán en el turismo de masas", Rubrica Contemporanea, 7-13 (2018), pp. 23-39.

36 Connell, Raewyn W. y Messerschmidt, James W.: "Hegemonic Masculinity. Rethinking the Concept", Gender \& Society, 19-6 (2005), pp. 829-859.

37 Anderson, Benedict: The Spectre of Comparisons: Nationalism, Southeast Asia and the World, Londres, Verso, 1998. 
ser significada sin aquellas otras masculinidades "no nacionales" respecto a las que se define y con las que "compite", bien para desmarcarse, bien para aproximarse a ellas ${ }^{38}$. Aunque parezca funcionar de forma autónoma e independiente, lo hace inevitablemente en relación implícita o explícita con una serie de Otros. Lo he señalado en el apartado anterior al discutir la relevancia que tienen los ejes civilizaciónbarbarie o modernidad-atraso para pensar la relación entre nación y masculinidad en el mundo contemporáneo. George Mosse lo señaló también de pasada al afirmar que la respetabilidad sexual de las naciones protestantes "modernas" del Norte se articuló mediante la imaginación de un Sur europeo católico habitado por unos sujetos masculinos que desbordaban supuestamente los límites morales que aquellos mismos se habían autoimpuesto ${ }^{39}$. Este proceso ha sido bien analizado en contextos coloniales como la India británica o la América y el África españolas, en los que el colonizado fue decisivo en la construcción de la masculinidad imperial de los sujetos metropolitanos ${ }^{40}$.

El proceso no es solo de ida, sino también de vuelta. Los estudios sobre estos y otros espacios coloniales ponen de manifiesto el carácter dialógico del proceso de construcción de las masculinidades nacionales. Las representaciones que hicieron los británicos de los bengalíes u otros pueblos colonizados del subcontinente participaron en el debate para fijar el significado de la masculinidad nacional india durante el proceso de independencia y posteriormente ${ }^{41}$. El diálogo funciona pues en múltiples direcciones. Un ejemplo representativo lo encontramos en Oriente Próximo. En respuesta al estereotipo transnacional antisemita que dibujaba al judío como un ser débil y afeminado, el sionismo enarboló la imagen de un "judío muscular" que acabaría haciendo suya el nuevo Estado de Israel. Esta concepción viril y militarista del judío se afirmó mediante su dominio sobre una población árabe descrita con rasgos "femeninos". Paradójicamente, la respuesta a este estereotipo y a esta dominación por parte del nacionalismo palestino fue la misma: una concepción viril de la masculinidad nacional de Palestina cuya hegemonía tuvo consecuencias para las

38 Slootmaeckers, Koen: "Nationalism as Competing Masculinities: Homophobia as a Technology of Othering for Hetero- and Homonationalism", Theory and Society, 48 (2019), pp. 239-265. En el caso español, esto se observa, por ejemplo, en la atracción que, a principios del siglo XX suscitó el modelo del gentleman entre diversos autores españoles; Martínez del Campo, Luis G.: “La educación del 'gentleman’ español. La influencia británica sobre la elite social española (1898-1936)", Ayer, 89 (2013), pp. 123-144. Esa atracción no implicaba única ni necesariamente imitación, sino una adaptación selectiva; Castro, David: "Juan Belmonte y la renovación de la masculinidad nacional”, Stvdia Historica. Historia contemporánea, 38 (2020).

39 Mosse, George L.: Nationalism and Sexuality..., p. 20.

40 Sinha, Mrinalini: Colonial Masculinities...; Torres, Gemma (coord.): L'home espanyol davant dels seus altres: masculinitat, colonialitat i classe, Rubrica Contemporanea, 7-13 (2018); Garcia Balañà, Albert: "No hay ningún soldado que no tenga una negrita. Raza, género, sexualidad y nación en la experiencia metropolitana de la guerra colonial (Cuba, 1895-1898)", en Xavier Andreu (ed.): Vivir la nación. Nuevos debates sobre el nacionalismo español, Granada, Comares, 2019, pp. 153-186; Torres, Gemma: La virilitat d'Espanya a l'Ałfrica... Sobre la persistencia de estas dinámicas en la España reciente, Santamaría, Sara: "Una nación moderna. Masculinidades españolas postimperiales frente a Guinea Ecuatorial”, Stvdia Historia. Historia contemporánea, 38 (2020), pp. 175-199.

41 Sinha, Mrinalini: Colonial Masculinities...; Banerjee, Sikata: Make Me a Man! Masculinity, Hinduism, and Nationalism in India, Nueva York, State University of New York Press, 2005. El proceso se repite para el caso de Irlanda, Banerjee, Sikata: Muscular Nationalism: Gender, Violence, and Empire in India and Ireland, 19142004, Nueva York, New York University Press, 2012; Beatty, Aidan: Masculinity and Power in Irish Nationalism, 1884-1938, Londres, Palgrave Mamillan, 2018. 
mujeres árabes ${ }^{42}$. Este tipo de dinámicas, como se observa en el caso español, no sólo se producen en contextos imperiales ${ }^{43}$.

El concepto de "masculinidad nacional" resulta útil, por tanto, si tenemos siempre presente su dimensión transnacional y lo libramos de todo esencialismo. La relevancia histórica de este concepto es evidente. Que no exista ninguna "masculinidad nacional" esencial, no quiere decir que esta categoría no actúe políticamente. De nuevo, la historia es la mejor aliada para entender cómo lo hace en cada contexto histórico concreto. Al mismo tiempo, la perspectiva histórica permite recordar que nunca hay una única "masculinidad nacional", sino múltiples concepciones de ésta que pugnan entre sí por devenir hegemónicas ${ }^{44}$. Estas "masculinidades nacionales" se definen las unas respecto de las otras. A menudo, aunque no necesariamente, adornan a sus rivales con rasgos "femeninos", o les acusan de desnaturalizar el carácter nacional con un comportamiento supuestamente impropio por "afeminado", un concepto cuyo significado es también histórico y, por lo tanto, cambiante ${ }^{45}$. "Feminidad" y "afeminamiento" no son, no obstante, las únicas variables a través de las cuales se llenan de significado estas masculinidades. También lo hacen al ser articuladas con otras categorías como la civilización, la modernidad, la religión, la clase, la raza, la sexualidad, la etnia o la identidad política ${ }^{46}$. Unas categorías que participan en cada contexto histórico concreto de una jerarquía particular y que implican y sancionan, por lo tanto, una configuración determinada de relaciones de poder ${ }^{47}$.

Por todas estas razones, es mejor hablar de "masculinidades nacionales", o bien de formas distintas de entender la masculinidad nacional. Señalar su pluralidad no significa obviar la necesidad de estudiar las que fueron hegemónicas en cada momento y contexto concreto, así como las consecuencias para los sujetos históricos del pasado de su preeminencia. Ahora bien, entendiendo que toda hegemonía es siempre contestada. Aquellas concepciones de la masculinidad marginadas del proyecto nacional hegemónico no son simples víctimas pasivas de su situación, sino que pueden acabar discutiendo, modificando o subvirtiendo dicho modelo hegemónico, pues toda hegemonía es siempre inestable ${ }^{48}$. La transformación puede ser especialmente profunda en algunos momentos en los que, por diversas circunstancias, se considera que se está produciendo una fractura en el ideal de masculinidad nacional hegemónico. Es decir, cuando se produce una "crisis de masculinidad nacional". Ésta puede ser el resultado de la ansiedad generada por la percepción de un desfase entre el "ideal" de masculinidad nacional y su "realidad", como se habría producido en España tras el Desastre del 98, pero también durante la pugna por establecer una masculinidad

42 Mayer, Tamar: "From Zero to Hero: Masculinity in Jewish Nationalism", en Tamar Mayer (ed.): Gender Ironies of Nationalism. Sexing the Nation, Nueva York, Routledge, 2000, pp. 283-307; Massad, Joseph: "Conceiving the Masculine: Gender and Palestinian Nationalism", Middle East Journal, 49-3 (1995), pp. 467-483.

43 Véase la nota 26.

44 Aresti, Nerea: "El Don Juan español, un símbolo polémico para una nación plural (1900-1940)", en Xavier Andreu (ed.): Vivir la nación..., pp. 187-212.

45 Spear, Gary: "Shakespeare's Manly Parts: Masculinity and Effeminacy in Troilus and Cressida", Shakespeare Quarterly, 44-4 (1993), pp. 409-422; Cohen, Michèle: Fashioning Masculinity...; Dudink, Stefan: "Masculinity, Effeminacy, Time...".

46 Ellis, Heather y Meyer, Jessica (eds.): Masculinity and the Other: Historical Perspectives, Newcastle upon Tyne, Cambridge Scholars Publishing, 2009.

47 Mayer, Tamar: "Gender Ironies of Nationalism. Setting the Stage”, en Tamar Mayer (ed.), Gender Ironies of Nationalism..., pp. 1-19.

48 Domínguez, Pablo y Wendt, Simon (eds.): Masculinities and the Nation in the Modern World, Between Hegemony and Marginalization, Nueva York, Palgrave Macmillan, 2015. 
nacional como hegemónica frente a las demás o por las propias transformaciones en la manera de entender las relaciones de género o la sexualidad ${ }^{49}$. En estos contextos la "masculinidad nacional" pasa a ocupar el centro del debate político ${ }^{50}$.

En cualquier caso, más allá de estos momentos críticos, hay que tener en cuenta que la relación entre la nación y la masculinidad es siempre una relación inestable, como lo son las dos categorías sobre las que se funda. En los últimos años, la crítica feminista ha discutido algunos de los pilares de la historia del género y ha abierto la puerta a cuestionar una concepción excesivamente consistente y estacionaria de las relaciones que se establecen en el mundo contemporáneo entre la nación y la masculinidad.

\section{Nación y masculinidad: una relación inestable}

En su seminal estudio sobre la aparición de la masculinidad moderna y del nacionalismo contemporáneo, George Mosse parte, como ya he señalado, de una concepción estable y homogénea del "arquetipo" masculino moderno. La masculinidad acaba siendo así fundamentalmente una, y sirve principalmente como una herramienta fija a la que habrían recurrido los nacionalistas contemporáneos para apuntalar sus proyectos. Las naciones modernas se habrían aprovechado de este modo de unas relaciones de género ya existentes y aparentemente estables e inmóviles; de unos ideales de género bien asentados previamente que en la propuesta de Mosse acaban siendo, en última instancia, naturalizados ${ }^{51}$.

Una de las aportaciones fundamentales de la crítica feminista a la teoría de las naciones ha sido, por el contrario, la de subrayar el proceso contrario: cómo el nacionalismo participa en la construcción de la diferencia sexual y la importancia que esto tuvo en la legitimación del gobierno de las múltiples diferencias que existen en el seno de toda comunidad nacional. Las metáforas familiares resultaron, por ejemplo, fundamentales, pues permitieron proyectar las relaciones de poder "naturalmente" existentes entre los diversos miembros de la unidad familiar a toda la nación en su conjunto $^{52}$. Nira Yuval-Davis ha inventariado las funciones y espacios diferenciados que prescriben los nacionalismos contemporáneos a los hombres y a las mujeres partiendo de estas metáforas: por un lado, limitan la capacidad de acción de estas últimas en los movimientos nacionalistas; por el otro, las convierten en iconos de la nación, en sus reproductoras culturales y biológicas y en salvaguardas de su honor ${ }^{53}$. Es decir, Yuval-Davis incide en cómo el nacionalismo excluye a las mujeres de las esferas públicas nacionales, convirtiéndolas fundamentalmente en figuras simbólicas y pasivas, y situándolas fuera del tiempo ${ }^{54}$. Como señalan otras autoras, los hombres, por su parte,

49 Aresti, Nerea: "La historia de género...".

50 Kimmel, Michael: Manhood in America...

51 "La nación adoptó el ideal de masculinidad como suyo propio (...)"; Mosse, George L.: La imagen del hombre..., p. 66. Cursiva mía.

52 Hunt, Lynn: The Family Romance of the French Revolution, Londres, Routledge, 1992; Sommer, Doris: Foundational Fictions: the National Romances of Latin America, Berkeley, University of California Press, 1993; McClintock, Anne: Imperial Leather. Race, Gender and Sexuality in the Colonial Contest, Nueva York, Routledge, 1995, pp. 352-389; Hall, Catherine: "The Rule of Difference: Gender, Class and Empire in the Making of the 1832 Reform Act”, en Ida Blom, Karen Hagemann y Catherine Hall (eds.): Gendered Nations..., pp. 107-135.

53 Yuval-Davis, Nira: Gender \& Nation, Londres, Sage, 1997.

54 Cusack, Tricia: "Janus and Gender: Women and the Nation's Backward Look", Nations and Nationalism, 6-4 (2000), pp. 541-561; Wenk, Silke: “Gendered Representations of the Nation's Past and Future”, en Ida Blom, 
son pensados desde el nacionalismo como los activos protagonistas de una comunidad política entendida como una "fraternidad masculina" sustentada en una camaradería horizontal y caracterizada por rasgos como la dominación, la violencia o la guerra ${ }^{55}$.

Sin embargo, esta manera de entender la relación entre género y nación, si es aceptada como normativa, puede acabar reforzando una comprensión demasiado rígida de las múltiples y fluidas relaciones que se producen entre la nación y los sujetos sexuados en el mundo contemporáneo. Ahora bien, si no existen ni una feminidad ni una masculinidad esenciales, derivadas de la naturaleza de los cuerpos en los que habitan, tampoco se articulan siempre del mismo modo con el nacionalismo o con la identidad nacional ${ }^{56}$. No existe, por ejemplo, una única manera de entender las relaciones familiares y de proyectar, a través de ellas, el rol que deben ocupar los hombres y las mujeres en el seno de la comunidad nacional. Por ejemplo, en el Japón autoritario del siglo XIX fue la figura del padre la que dominó una simbología nacional y familiar en la que la madre/esposa ocupaba un lugar subsidiario. El Emperador era representado como el padre de una nación a quien sus hijos (y mujeres) debían obediencia ciega ${ }^{57}$. Por otro lado, si bien la nación ha sido caracterizada y celebrada recurrentemente con cuerpo de mujer desde la Revolución Francesa, no siempre ni necesariamente lo ha sido de este modo. Ni siquiera durante la Revolución fue ésta la única manera de representarla, ni la predominante en todo momento: como advirtió Lynn Hunt, en la era del Terror, los jacobinos prefirieron a Hércules antes que a Marianne para representar a una nación francesa asediada por múltiples enemigos ${ }^{58}$. Ni la recién creada nación australiana, ni el primer nacionalismo vasco, optaron tampoco por figuras femeninas para imaginar$\mathrm{se}^{59}$. Para los nacionalismos fascistas, fueron la virilidad y la fortaleza de unos cuerpos masculinos duros e impenetrables los que mejor simbolizaban los valores nacionales ${ }^{60}$. Además, que la nación se vistiera de mujer no quiere decir que lo hiciera necesariamente con ropajes "femeninos": en las revoluciones liberales, la Minerva guerrera fue a menudo invocada como uno de los símbolos de la patria en armas ${ }^{61}$.

Una identificación excesivamente rígida entre el nacionalismo y una masculinidad moderna supuestamente estable y homogénea, que se asocia además exclusivamente con los "hombres", puede derivar fácilmente hacia el esencialismo ${ }^{62}$. Desde

Karen Hagemann y Catherine Hall (eds.): Gendered Nations..., pp. 63-77.

55 Nagel, Joane: "Masculinity and Nationalism: Gender and Sexuality in the Making of Nations", Ethnic and Racial Studies, 21-2 (1998), pp. 242-269.

56 McClintock, Anne: Imperial Leather...; Sinha, Mriralini: Colonial Masculinities...

57 Blom, Ida: "Gender and Nation in International Comparison", en Ida Blom, Karen Hagemann y Catherine Hall (eds.), Gendered Nations..., pp. 3-26; Germer, Andrea, Mackie, Vera y Wöhr, Ulrike (eds.): Gender, Nation and State in Modern Japan, Nueva York, Routledge, 2017.

58 Hunt, Lynn: The Family Romance...

59 Lake, Marilyn: "The Ambiguities for Feminists of National Belonging: Race and Gender in the Imagined Australian Community", en Ida Blom, Karen Hagemann y Catherine Hall (eds.): Gendered Nations..., pp. 159-176; Aresti, Nerea: "De heroínas viriles a madres de la patria. Las mujeres y el nacionalismo vasco (1893-1937)", Historia y Política, 31 (2014), pp. 281-308.

60 Theveleit, Klaus: Males Fantasies, Minneapolis, University of Minnesota Press, 1987; Box, Zira: "Cuerpo y nación: sobre la España vertical y la imagen del hombre", Ayer, 107 (2017), pp. 205-228; Box, Zira: "Metáforas de linealidad, género y fascismo español. Una propuesta de análisis socio-metafórico", REIS: Revista Española de Investigaciones Sociológicas, 164 (2018), pp. 41-56. Esta representación viril de la nación fue fundamental también para los reaccionarios; Torres, Gemma: "La nación viril. Imágenes masculinas de España en el africanismo reaccionario después de la derrota de Annual (1921-1927)”, Ayer, 106 (2017), pp. 133-158.

61 Banti, Alberto M.: L'onore della nazione...

62 Esa deriva se observa incluso en el planteamiento de Joan Nagel quien, tras combinar a Mosse con el concepto de "masculinidad hegemónica" de Connell, parece no dejar espacio a formas de masculinidad no nacionalistas, 
el nacimiento del mundo contemporáneo, los ideales de masculinidad hegemónicos se han asociado habitualmente con el nacionalismo, así como con la guerra o con la política. Ahora bien, esta asociación es un producto de la historia, no obedece a la mayor propensión de una supuesta esencia masculina a tomar las armas o a ocupar el espacio público ${ }^{63}$. Incluso en los lugares y en los momentos en los que se ha impuesto con mayor crueldad esta identificación entre masculinidad, nación y violencia, como ocurrió durante las últimas guerras en los Balcanes, lo hizo frente a otros modelos de masculinidad existentes que rehuían dicha identificación y que, a pesar de ser marginados y perseguidos durante el conflicto, pudieron ser movilizados e incluso convertirse en hegemónicos posteriormente ${ }^{64}$.

En definitiva, el vínculo que se establece en el mundo contemporáneo entre el nacionalismo y la masculinidad no puede darse por supuesto, sino que debe analizarse históricamente ${ }^{65}$. Tampoco debería estudiarse sin aplicar un enfoque relacional o sin atender a la acción de los sujetos históricos. Sikata Banerjee, siguiendo los pasos de Sinha, ha analizado, por ejemplo, la formación de un "nacionalismo muscular" hindú en las últimas décadas del siglo XIX como reacción a la construcción del pueblo colonizado indio en tanto que "afeminado" por la mirada imperial británica. Esta masculinización del nacionalismo hindú tuvo importantes consecuencias para las mujeres nacionalistas indias, que debían ser a partir de entonces "protegidas" por sus hombres y abandonar una esfera pública en la que habían sido muy activas anteriormente. No obstante, muchas de estas mujeres se mantuvieron en la lucha negociando su participación en ella al hacer suyos modelos aceptables como el de la madre heroica, la mujer casta o la guerrera viril célibe que, a su vez, podían desestabilizar y subvertir ese nacionalismo muscular hindú hegemónico ${ }^{66}$. Al mismo tiempo, estos modelos de masculinidad nacional convivieron en el siglo XX con otros de rasgos "femeninos" como el que encarnaron el líder espiritual Mahatma Gandhi u otros destacados protagonistas de la descolonización del subcontinente ${ }^{67}$.

Estos ejemplos iluminan de nuevo los problemas resultantes de analizar la relación entre nación y masculinidad desde el binarismo. Como ya he apuntado anteriormente, la masculinidad (o el nacionalismo) no es sólo cosa de hombres. La masculinidad heroica, asociada habitualmente en el mundo contemporáneo a la retórica nacionalista, ha sido producida históricamente y en todas partes por todo tipo de cuerpos sexuados, no sólo por los varones ${ }^{68}$. Esta cuestión ha sido especialmente explorada por diversas historiadoras vascas. Las mujeres viriles, como han señalado Bakarne Altonaga para el foralismo guipuzcoana dieciochesco, Nerea Aresti para

militaristas, dominantes e imperialistas; Nagel, Joan: "Masculinity and Nationalism...".

63 Como tampoco existe una inclinación natural de las mujeres hacia la paz o hacia la esfera doméstica. Naturalizar la relación entre hombres, nacionalismo y guerra es la contrapartida de esencializar una relación entre mujeres, indiferencia nacional y pacifismo que ha sido ampliamente discutida por la historiografía feminista. Para el caso español, véanse las reflexiones de Blasco, Inmaculada: “¿Qué mujeres para qué España?: feminidad y nación en el feminismo español (1900-1923)", en Henar Gallego (ed.): Feminidades y masculinidades..., pp. 105-126.

${ }_{64}$ Bracewell, Wendy: "Rape in Kosovo: Masculinity and Serbian Nationalism", Nations and Nationalism, 6-4 (2000), pp. 563-590.

65 Tampoco el que se establece entre el nacionalismo y el patriarcado; Waetjen, Thembisa: "The Limits of Gender Rhetoric for Nationalism: A Case Study from Southern Africa", Theory and Society, 30 (2001), pp. 121-152.

66 Banerjee, Sikata: Make Me a Man!... Una vez más, los patrones se repiten en otros enclaves imperiales como Irlanda; Banerjee, Sikata: Muscular Nationalism...

67 Holden, Philip: Autobiography and Decolonization. Modernity, Masculinity and the Nation-State, Madison, The University of Wisconsin Press, 2008.

${ }_{68}$ Halberstam, Judith: Female Masculinity..., p. 2. 
el nacionalismo vasco de entre siglos y el español bajo la dictadura de Primo de Rivera, y Miren Llona en relación con la figura de Dolores Ibárruri, cumplieron un papel destacado en numerosos movimientos autonomistas o nacionalistas, aunque su presencia fuera percibida al mismo tiempo y a menudo como amenazante ${ }^{69}$.

Otro tanto puede afirmarse en relación con la heteronormatividad. Numerosos trabajos, empezando nuevamente por Mosse, han subrayado que ésta ha sido característica del modo hegemónico en que se han combinado nación y masculinidad en la contemporaneidad $^{70}$. Joan B. Landes, por ejemplo, ha sugerido que el erotismo funcionó desde la Revolución Francesa como una escuela de patriotismo, al tiempo que este último permitió enseñar una nueva forma de entender y dirigir los deseos amorosos. Los hombres fueron animados a amar a su patria del mismo modo en que debían amar a su mujer o a su prometida. Su hombría fue identificada y afirmada en tanto que ciudadanos del nuevo Estado nacional, pero también en tanto que sujetos heterosexuales cuyos deseos eran disciplinados y dirigidos hacia unos cuerpos femeninos legítimos y circunscritos al ámbito familiar ${ }^{71}$. Asimismo, se ha subrayado la importancia que tuvieron los nuevos discursos médicos sobre la "homosexualidad" en los debates sobre la degeneración racial y nacional del fin-de-siècle y de las primeras décadas del siglo $\mathrm{XX}$, hasta el punto de convertirse en elementos centrales de las "crisis de masculinidad nacional" que se sucedieron entonces, como han señalado para el caso español Francisco Vázquez García y Richard Cleminson ${ }^{72}$. Con todo, trabajos como los de Jasbir K. Puar han puesto de relieve que la conexión entre nacionalismo y heteronormatividad no resulta tampoco necesaria. El nacionalismo no es per se homófobo o heteronormativo, aunque en muchas ocasiones lo $\mathrm{sea}^{73}$. Al fin y al cabo, tanto el nacionalismo, como el género, como la sexualidad, son construcciones sociales y culturales y, como tales, pueden ser construidas (y articuladas unas con otras) de formas muy dispares.

\section{A modo de conclusión: la historia y la vuelta del sujeto}

Lo que sugieren los diversos trabajos que han analizado la relación entre nación y masculinidades en las últimas décadas es que en el mundo contemporáneo se establece entre ambas categorías una relación particularmente intensa. Ahora bien, los papeles que se asignan a hombres y a mujeres dentro de la comunidad nacional, o el significado de lo masculino y lo femenino, no son una simple "traducción" de una

69 Altonaga, Bakarne: "Mujeres viriles en el siglo XVIII: la construcción de la feminidad por el discurso foralista de Manuel de Larramendi", Historia contemporánea, 52 (2016), pp. 9-42; Aresti, Nerea: "De heroínas viriles..." y "A Fight for Real Men: Gender and Nation-Building during the Primo de Rivera Dictatorship (1923-1930)", European History Quarterly, 50-2 (2020), pp. 248-265; Llona, Miren: "La imagen viril de Pasionaria: los significados simbólicos de Dolores Ibárruri en la II República y la Guerra Civil”, Historia y Politica, 36 (2016), pp. 263-287.

70 Mosse, George L.: Nationalism and Sexuality...; Mayer (ed.): Gender Ironies of Nationalism...

71 Landes, Joan B.: Visualizing the Nation. Gender, Representation, and Revolution in Eighteenth-Century France, Ithaca (NY), Cornell University Press, 2001; y Landes, Joan B.: "Republican Citizenship and Heterosocial Desire: Concepts of Masculinity in Revolutionary France", en Stefan Dudink, Karen Hagemann y John Tosh (eds.): Masculinities in Politics and War..., pp. 96-115. Véase también Sommer, Doris: Foundational Fictions...

72 Vázquez García, Francisco y Cleminson, Richard: Los Invisibles: una historia de la homosexualidad en España, 1850-1939, Granada, Comares, 2011.

73 De hecho, el "homonacionalismo" puede servir para reforzarlo y para legitimar otras relaciones de poder a escala local o global; Puar, Jasbir K.: Ensamblajes terroristas. El homonacionalismo en tiempos queer, Barcelona, Bellaterra, 2017; Santamaría, Sara: “Una nación moderna...”. 
división de género previamente existente. La nación no es simplemente la traslación al ámbito de la comunidad política de unas determinadas formas de entender las relaciones de género o la sexualidad, sino una de las variables que participan en su configuración. Por ello, estos trabajos evidencian la necesidad de rehuir una concepción estable de las masculinidades (y de las feminidades) a la hora de analizar cómo se articulan en relación con otra categoría igualmente inestable como la nación. Sobre todo, plantean la relevancia de analizar cómo se construyen mutuamente esas categorías, y en relación con otras, en cada contexto histórico concreto ${ }^{74}$.

Por otro lado, estos trabajos sugieren que la construcción nacional y la de las formas de entender la masculinidad y la feminidad son procesos que actúan en ambas direcciones y se refuerzan mutuamente. El nacionalismo funciona a menudo en el mundo contemporáneo como un lenguaje a través del cual la virilidad es expresada y ejercida ${ }^{75}$. Por ello, la afirmación nacional o el nacionalismo pueden funcionar como mecanismos mediante los cuales un sujeto ve reconocido por sus pares una masculinidad que "aún" no se posee, que ha sido puesta en entredicho o que se siente amenazada por circunstancias muy diversas ${ }^{76}$. La nación puede servir de ancla para intentar fijar una subjetividad masculina, del mismo modo que un determinado ideal de masculinidad puede ser invocado para estabilizar una nación que se perciba a sí misma en crisis. Por esta razón, determinados lenguajes -así como espacios y sonidos nacionales- sirvieron para construir al mismo tiempo la nación contemporánea y sus formas hegemónicas de masculinidad, como ha señalado Josephine Hoegaerts para el caso belga ${ }^{77}$. Estas perspectivas ayudan a esclarecer los caminos que llevan a la nación y a la masculinidad a muchos sujetos y, por tanto, nos permiten comprender mejor los procesos de nacionalización y las formas de construir la diferencia sexual en el mundo contemporáneo.

Asimismo, de lo anteriormente expuesto se deduce que no existe nunca una masculinidad nacional -como no existe un único modo de concebir la masculinidad-, sino múltiples formas de entender la relación entre nación y masculinidad que pugnan por fijar su significado y devenir hegemónicas. Para llenarse de significado, toda "masculinidad nacional" necesita declinarse en relación no sólo con la feminidad, sino también con Otras masculinidades delimitadas a partir de otras categorías (religión, raza, sexualidad, clase, etc.). Podría afirmarse que es la misma proclamación de estas diferencias, más que ningún contenido esencial, lo que permite delimitar en cada momento el significado de la "masculinidad nacional". A su vez, la relación que ésta establece con cada una de estas categorías no siempre es la misma o igual de intensa. Por ello resulta fundamental atender a qué categorías son, en cada caso concreto, las más relevantes y por qué. La de género no es necesariamente la determinante a la hora de imaginar la nación y de ordenar y regular sus diferencias. Como señala Sinha, la raza puede ser tanto o más importante, por ejemplo, en los contextos imperiales $^{78}$.

74 Sinha, Mrinalini: "Nations in an Imperial Crucible", en Philippa Levine (ed.): Gender and Empire, Oxford, Oxford University Press, 2004, pp. 181-202.

75 Mayer, Tamar: "Gender Ironies of Nationalism...".

76 Nagel, Joan: "Masculinity and Nationalism..."; Sohn, Anne-Marie: "Nation et apprentisage de la masculinité. L'exemple des jeunes Français aux XIXe siècle”, Mélanges de la Casa de Velázquez, 42-2 (2012), pp. 143-160.

77 Hoegaerts, Josephine: Masculinity and Nationhood, 1830-1910. Constructions of Identity and Citizenship in Belgium, Nueva York, Palgrave Macmillan, 2014.

78 Sinha, Mriralini: "Nations in an Imperial Crucible...". 
Por otro lado, de lo hasta aquí expuesto se deriva la centralidad de los sujetos históricos en la institución, transformación y/o subversión de las formas hegemónicas de pensar la nación y la masculinidad en el mundo contemporáneo. Aceptando algunas críticas a las dificultades del concepto de "masculinidad hegemónica" para incorporar la problemática del sujeto, la propia Connell ha reconocido que la masculinidad sólo existe "impersonally in culture as a subject position in the process of representation, in the structures of language and other symbol systems". La práctica individual "may accept and reproduce this positioning, but may also confront and contest it" "79.

Esta "vuelta al sujeto" no puede ser ingenua. No podemos hablar ya, obviamente, de sujetos homogéneos, unitarios o ahistóricos. Hablamos de sujetos que se constituyen como tales posicionándose en relación con múltiples identidades a lo largo de su vida y a partir de sus propias "experiencias" dan sentidos diversos y cambiantes a su propia masculinidad y nacionalidad en función de las circunstancias en que éstas son actuadas; de sujetos no sólo racionales, sino también emocionales. Las emociones, entendidas desde su dimensión política, y como elementos cultural e históricamente construidos, se convierten en piezas fundamentales para cimentar esas identidades múltiples e inestables. Son claves, de este modo, para entender cómo se fijan en cada momento las relaciones entre la nación y la masculinidad ${ }^{81}$.

Por otro lado, no podemos concebir a los sujetos históricos, tampoco, como absolutamente autónomos y conscientes de sus actos. La masculinidad y la nación son practicadas, en gran medida, como habitus que se aprenden, se reproducen y que resultan, a menudo, difíciles de cuestionar ${ }^{82}$. Pero, en cualquier caso, las estructuras no anulan la capacidad de acción de los sujetos. Lejos de ser inmóviles, las mismas estructuras se encuentran en continua transformación por la propia acción de esos sujetos que las sostienen o las erosionan ${ }^{83}$. Como señala Mayer siguiendo a Judith

79 Connell, Raewyn W.: The Men and the Boys, Cambridge, Polity Press, 2000, p. 30.

80 Sobre la vuelta al sujeto y a la experiencia en relación con la cuestión nacional véanse Archilés, Ferran: "Lenguajes de nación. Las 'experiencias de nación' y los procesos de nacionalización: propuestas para un debate", Ayer, 90 (2013), pp. 91-114; Molina, Fernando: "La nación desde abajo. Nacionalización, individuo e identidad nacional", Ayer, 90 (2013), pp. 39-63; Moreno, Raúl: "La nación de los sujetos: propuestas para una investigación de los fenómenos nacionales a comienzos de la época contemporánea", Rubrica Contemporanea, 6-11 (2017), pp. 5-23.

81 Ahmed, Sarah: The Cultural Politics of Emotion, Edimburgo, Edinburgh University Press, 2014. Silvana Patriarca, por ejemplo, ha demostrado la importancia que tuvo la "vergüenza", sentida al mismo tiempo de forma personal y colectiva, para propiciar el alistamiento de muchos italianos a la causa del Risorgimento; Patriarca, Silvana: "A Patriotic Emotion: Shame and the Risorgimento", en Silvana Patriarca y Lucy Riall (eds.): The Risorgimento Revisited. Nationalism and Culture in Nineteenth-Century Italy, Nueva York, Palgrave Mamillan, 2012, pp. 134-151. Para el caso español, Gemma Torres analiza cómo fueron experimentadas a través de las emociones las identidades nacionales y de género por los diversos protagonistas de las guerras del Rif, Torres, Gemma: "Emociones viriles y la experiencia de la nación imperial en las Guerras del Rif (1909-1927)", Stvdia Historica. Historia contemporánea, 38 (2020), pp. 99-127.

82 Bourdieu, Pierre: La dominación masculina, Barcelona, Anagrama, 2000; French, Henry y Rothery, Frank: "Hegemonic Masculinities?". Respecto a la reproducción inconsciente de las identidades nacionales Billig, Michael: Nacionalisme banal, Catarroja, Afers, 2006; Archilés, Ferran: “¿En el rincón feliz? Habituarse a la nación o a la identidad nacional como experiencia (in)voluntaria", en Marta García Carrión y Sergio Valero (coords.): Tejer identidades: Socialización, cultura y política en época contemporánea, Valencia, Tirant lo Blanch, 2018, pp. 19-43.

83 Sewell Jr., William H.: Logics of History. Social Theory and Social Transformation, Chicago, University of Chicago Press, 2005. 
Butler, quienes forman la nación son unos sujetos sexuados cuya "performatividad" construye y mantiene no sólo su propia identidad de género, sino la de toda la nación en su conjunto ${ }^{84}$. Ahora bien, dado que todas estas categorías se construyen en oposición o en relación con unos Otros sobre los que intentan establecer unas relaciones jerárquicas y de poder, en el proceso de afirmar su hegemonía se convierten en territorios en disputa; en espacios desde los que esas categorías hegemónicas pueden ser contestadas y transformadas. Esto es lo que les confiere, inevitablemente, su historicidad.

\section{Referencias bibliográficas}

Ahmed, Sarah: The Cultural Politics of Emotion, Edimburgo, Edinburgh University Press, 2014.

Alicia Jagoe, Eva-Lynn: "Asociaciones afectivas: literatura y política en la Argentina del siglo XIX o "cómo ser europeo en América”, en Anna Peluffo e Ignacio M. Sánchez Prado (eds.), Entre hombres: masculinidades del siglo XIX en América Latina, Madrid y Frankfurt, Iberoamericana-Vervuert, 2010, pp. 109-122.

Altonaga, Bakarne: "Mujeres viriles en el siglo XVIII: la construcción de la feminidad por el discurso foralista de Manuel de Larramendi”, Historia contemporánea, 52 (2016), pp. $9-42$

Anderson, Benecit: The Spectre of Comparisons: Nationalism, Southeast Asia and the World, Londres, Verso, 1998.

Andreu, Xavier: El descubrimiento de España. Mito romántico e identidad nacional, Barcelona, Taurus, 2016.

Andreu, Xavier: "Tambores de guerra y lágrimas de emoción. Nación y masculinidad en el primer republicanismo", en Aurora Bosch e Ismael Saz (coords.): Izquierdas y derechas ante el espejo: culturas politicas en conflicto, Valencia, Tirant lo Blanch, 2016, pp. 91-118.

Andreu, Xavier: "El género de las naciones. Un balance y cuatro propuestas", Ayer, 106 (2017), pp. 21-46.

Andreu, Xavier: "A Fatherland of Free Men: Virility and 'Frailty' in Spanish Liberalism (1808-1814)", Gender and History, 33-3 (2021).

Archilés, Ferran: "Lenguajes de nación. Las ‘experiencias de nación’ y los procesos de nacionalización: propuestas para un debate", Ayer, 90 (2013), pp. 91-114.

Archilés, Ferran: "¿En el rincón feliz? Habituarse a la nación o a la identidad nacional como experiencia (in)voluntaria", en Marta García Carrión y Sergio Valero (coords.): Tejer identidades: Socialización, cultura y política en época contemporánea, València, Tirant lo Blanch, 2018, pp. 19-43.

Aresti, Nerea: "A la nación por la masculinidad. Una mirada de género a la crisis del 98", en Mary Nash (ed.): Feminidades y masculinidades. Arquetipos y prácticas de género, Madrid, Alianza Editorial, 2014, pp. 47-74.

Aresti, Nerea: "De heroínas viriles a madres de la patria. Las mujeres y el nacionalismo vasco (1893-1937)", Historia y política, 31, 2014, pp. 281-308.

Aresti, Nerea: "La historia de género y el estudio de las masculinidades. Reflexiones sobre conceptos y métodos", en Henar Gallego (ed.): Feminidades y masculinidades en la historiografía de género, Granada, Comares, 2018, pp. 173-194.

${ }^{84}$ Mayer, Tamar: "Gender Ironies of Nationalism...", p. 5. 
Aresti, Nerea: "El Don Juan español, un símbolo polémico para una nación plural (19001940)", en Xavier Andreu (ed.): Vivir la nación. Nuevos debates sobre el nacionalismo español, Granada, Comares, 2019, pp. 187-212.

Aresti, Nerea: "La historia de las masculinidades, la otra cara de la historia de género", Ayer, 117 (2020), pp. 333-347.

Aresti, Nerea: "A Fight for Real Men: Gender and Nation-Building during the Primo de Rivera Dictatorship (1923-1930)”, European History Quarterly, 50-2 (2020), pp. 248265.

Aresti, Nerea y Martykánová, Darina (coords.): Masculinidades, nación y civilización en la España contemporánea, Cuadernos de Historia Contemporánea, 39 (2017).

Aresti, Nerea, Peters, Karin y Brühne, Julia (coords.): ¿La España invertebrada? Masculinidad y nación a comienzos del siglo XX, Granada, Comares, 2016.

Armengol, Josep M. (ed.): Queering Iberia. Iberian Masculinities at the Margins, Nueva York, Peter Lang, 2012.

Banerjee, Sikata: Make Me a Man! Masculinity, Hinduism, and Nationalism in India, Nueva York, State University of New York Press, 2005.

Banerjee, Sikata: Muscular nationalism: gender, violence, and empire in India and Ireland, 1914-2004, Nueva York, New York University Press, 2012.

Banister, Judith: Masculinity, Militarism and Eighteenth-Century Culture, 1689-1815, Cambridge, Cambridge University Press, 2018.

Banti, Alberto M.: L'onore della nazione. Identità sessuali e violenza nel nazionalismo europeo dal XVIII secolo alla Grande Guerra, Turín, Einaudi, 2005.

Beatty, Aidan: Masculinity and Power in Irish Nationalism, 1884-1938, Londres, Palgrave Macmillan, 2018.

Billig, Michael: Nacionalisme banal, Catarroja, Afers, 2006.

Blasco, Inmaculada: “¿Qué mujeres para qué España?: feminidad y nación en el feminismo español (1900-1923)", en Henar Gallego (ed.): Feminidades y masculinidades en la historiografía de género, Granada, Comares, 2018, pp. 105-126.

Blom, Ida: "Gender and Nation in International Comparison", en Ida Blom, Karen Hagemann y Catherine Hall (eds.): Gendered Nations. Nationalisms and gender order in the long nineteenth century, Nueva York, Berg, 2000, pp. 3-26.

Blom, Ida, Hagemann, Karen y Hall, Catherine (eds.): Gendered Nations. Nationalisms and gender order in the long nineteenth century, Nueva York, Berg, 2000.

Bolufer, Mónica: “Civilización, costumbres y política en la literatura de viajes a España en el siglo XVIII”, Estudis: Revista de historia moderna, 29 (2003), pp. 255-300.

Bourdieu, Pierre: La dominación masculina, Barcelona, Anagrama, 2000.

Box, Zira: "Cuerpo y nación: sobre la España vertical y la imagen del hombre”, Ayer, 107 (2017), pp. 205-228.

Box, Zira: "Metáforas de linealidad, género y fascismo español. Una propuesta de análisis sociometafórico", REIS: Revista Española de Investigaciones Sociológicas, 164 (2018), pp. 41-56.

Bracewell, Wendy: "Rape in Kosovo: Masculinity and Serbian Nationalism", Nations and Nationalism, 6-4 (2000), pp. 563-590.

Castro, David: “Juan Belmonte y la renovación de la masculinidad nacional”, Studia Histórica. Historia contemporánea, 38 (2020). En prensa.

Chakrabarty, Dipesh: Provincializing Europe. Postcolonial Thought and Historical Difference, Princeton, Princeton University Press, 2008.

Chatterjee, Partha: The Nation and Its Fragments: Colonial and Postcolonial Histories, Princeton, Princeton University Press, 1993. 
Cohen, Michèle: Fashioning Masculinity: National Identity and Language in the Eighteenth Century, Londres, Routledge, 2002.

Colley, Linda: Britons. Forging the Nation 1707-1837, Londres, Yale University Press, 1992. Connell, Raewyn W.: Masculinities, Cambridge, Polity Press, 1995.

Connell, Raewyn W.: The Men and the Boys, Cambridge, Polity Press, 2000.

Connell, Raewyn W. y Messerschmidt, James W.: "Hegemonic Masculinity. Rethinking the Concept", Gender \& Society, 19-6 (2005), pp. 829-859.

Corbin, Alain: "La virilité reconsidérée au prisme du naturalisme" en Alain Corbin (dir.): Histoire de la virilité 2. Le triomphe de la virilité. Le XIXe siècle, París, Le Seuil, 2011, pp. 15-30.

Corbin, Alain (dir.): Histoire de la virilité 2. Le triomphe de la virilité. Le XIXe siècle, París, Le Seuil, 2011.

Cusack, Tricia: “Janus and Gender: Women and the Nation's Backward Look", Nations and Nationalism, 6-4 (2000), pp. 541-561.

Díaz Freire, José Javier: "Miguel de Unamuno: la feminización de la masculinidad moderna”, Cuadernos de Historia Contemporánea, 39 (2017), pp. 39-58.

Domínguez, Pablo y Wendt, Simon (eds.): Masculinities and the Nation in the Modern World. Between Hegemony and Marginalization, Nueva York, Palgrave Macmillan, 2015.

Dorlin, Elsa: La matrice de la race. Généalogie sexuelle et coloniale de la Nation française, París, La Découverte, 2009.

Dudink, Stefan: "Masculinity, Effeminacy, Time: Conceptual Change in the Dutch Age of Democratic Revolutions", en Stefan Dudink, Karen Hagemann y John Tosh (eds.): Masculinities in Politics and War. Gendering Modern History, Manchester, Manchester University Press, 2008, pp. 77-95.

Dudink, Stefan: "Multipurpose Masculinities. Gender and Power in Low Countries Histories of Masculinity”, BMGN-Low Countries Historical Review, 127-1 (2012), pp. 5-18.

Dudink, Stefan, Hagemann, Karen y Clark, Anna (eds.): Representing Citizenship. Male Citizenship in Modern Western Culture, Nueva York, Palgrave Macmillan, 2007.

Dudink, Stefan, Hagemann, Karen y Tosh, John (eds.): Masculinities in Politics and War. Gendering Modern History, Manchester, Manchester University Press, 2008.

Eley, Geoff: “Culture, Nation and Gender”, en Ida Blom, Karen Hagemann y Catherine Hall (eds.): Gendered Nations. Nationalisms and gender order in the long nineteenth century, Nueva York, Berg, 2000, pp. 27-40.

Ellis, Heather y Meyer, Jessica (eds.): Masculinity and the Other: Historical Perspectives, Newcastle upon Tyne, Cambridge Scholars Publishing, 2009.

Forth, Christopher E. y Taithe, Bertrand (eds.): French Masculinities: History, Culture and Politics, Nueva York, Palgrave Macmillan, 2007.

French, Henry y Rothery, Mark: "Hegemonic Masculinities? Assessing Change and Processes of Change in Elite Masculinity, 1700-1900”, en John H. Arnold y Sean Grady (eds.): What is Masculinity? Historical Dynamics from Antiquity to the Contemporary World, Basingstoke, Palgrave Macmillan, 2013, pp. 139-166.

Garcia Balañà, Albert: “"No hay ningún soldado que no tenga una negrita'. Raza, género, sexualidad y nación en la experiencia metropolitana de la guerra colonial (Cuba, 18951898)", en Xavier Andreu (ed.): Vivir la nación. Nuevos debates sobre el nacionalismo español, Granada, Comares, 2019, pp. 153-186.

Germer, Andrea, Mackie, Vera y Wöhr, Ulrike (eds.): Gender, Nation and State in Modern Japan, Nueva York, Routledge, 2017.

Gilmore, David: Manhood in the Making. Cultural Concepts of Masculinity, Londres, Yale University Press, 1990. 
González-Allende, Iker: Hombres en movimiento. Masculinidades españolas en los exilios y migraciones, 1939-1999, West Lafayette (Indiana), Purdue University Press, 2018.

Hagemann, Karen: “Of 'Manly Valor' and 'German Honor': Nation, War, and Masculinity in the Age of the Prussian Uprising against Napoleon", Central European Review, 30-2 (1997), pp. 187-220.

Hagemann, Karen, Mettele, Gisela y Rendall, Jane (eds.): Gender, War and Politics. Transatlantic Perspectives, 1775-1830, Londres, Palgrave Macmillan, 2010.

Halberstam, Judith: Female Masculinity, Durham, Duke University Press, 1998.

Hall, Catherine: "The Rule of Difference: Gender, Class and Empire in the Making of the 1832 Reform Act", en Ida Blom, Karen Hagemann y Catherine Hall (eds.): Gendered Nations. Nationalisms and gender order in the long nineteenth century, Nueva York, Berg, pp. 107-135.

Harvey, Karen: "The Century of Sex? Gender, Bodies, and Sexuality in the Long Eighteenth Century", The Historical Journal, 45-4 (2002), pp. 899-916.

Harvey, Karen y Shepard, Alexandra: "What Have Historians Done with Masculinity? Reflections on Five Centuries of British History, circa 1500-1950", Journal of British Studies, 44 (2005), pp. 274-280.

Herzfeld, Michael: Anthropology through the Looking-Glass. Critical Ethnography in the Margins of Europe, Cambridge, Cambridge University Press, 1987.

Hitchcock, Tim y Cohen, Michèle (eds.): English masculinities, 1660-1800, Londres, Longman, 1999.

Hoegaerts, Josephine: Masculinity and Nationhood, 1830-1910. Constructions of Identity and Citizenship in Belgium, Nueva York, Palgrave Macmillan, 2014.

Holden, Philip: Autobiography and Decolonization. Modernity, Masculinity and the NationState, Madison, The University of Wisconsin Press, 2008.

Horn, Maja: Masculinity After Trujillo: The Politics of Gender in Dominican Literature, Gainesville, University Press of Florida, 2014.

Hunt, Lynn: The Family Romance of the French Revolution, Londres, Routledge, 1992.

Irwin, Robert M.: Mexican Masculinities, Minneapolis, University of Minnesota Press, 2003.

Kimmel, Michael: Manhood in America. A Cultural History, Nueva York, Oxford University Press, 1996.

Lake, Marilyn: "The Ambiguities for Feminists of National Belonging: Race and Gender in the Imagined Australian Community", en Ida Blom, Karen Hagemann y Catherine Hall (eds.): Gendered Nations. Nationalisms and gender order in the long nineteenth century, Nueva York, Berg, 2000, pp. 159-176.

Landes, Joan B.: Visualizing the Nation. Gender, Representation, and Revolution in Eighteenth-Century France, Ithaca (NY), Cornell Univesity Press, 2001.

Landes, Joan B.: "Republican Citizenship and Heterosocial Desire: Concepts of Masculinity in Revolutionary France", en Stefan Dudink, Karen Hagemann y John Tosh (eds.): Masculinities in Politics and War. Gendering Modern History, Manchester, Manchester University Press, 2008, pp. 96-115.

Laqueur, Thomas: La construcción del sexo: cuerpo y género desde los griegos hasta Freud, València, Cátedra-Universitat de València, 1994.

Leerssen, Joep: El pensament nacional a Europa. Una història cultural, Catarroja, Afers, 2019.

Llona, Miren: "La imagen viril de Pasionaria: los significados simbólicos de Dolores Ibárruri en la II República y la Guerra Civil", Historia y política, 36 (2016), pp. 263-287. 
Maleĉková, Jitka: "Women in Perceptions of Uneven Development”, en Miroslav Hroch y Luda Klusáková (eds.): Criteria and Indicators of Backwardness. Essays on Uneven Development in European History, Praga, Variant, 1996, pp. 143-156.

Martin, Patricia Y.: “Why Can't Be a Man More Like a Woman? Reflections on Connell's Masculinities", Gender \& Society, 12-4 (1998), pp. 472-474.

Martínez del Campo, Luis G.: “La educación del ‘gentleman’ español. La influencia británica sobre la elite social española (1898-1936)”, Ayer, 89 (2013), pp. 123-144.

Martykánová, Darina y Víctor M. Núñez-García: “Ciencia, patria y honor: los médicos e ingenieros y la masculinidad romántica en España (1820-1860)", Stvdia Histórica. Historia contemporánea, 38 (2020), pp. 45-75.

Massad, Joseph: "Conceiving the Masculine: Gender and Palestinian Nationalism", Middle East Journal, 49-3 (1995), pp. 467-483.

Mayer, Tamar: "Gender Ironies of Nationalism. Setting the Stage", en Tamar Mayer (ed.): Gender Ironies of Nationalism. Sexing the Nation, Nueva York, Routledge, 2000, pp. 1-19.

Mayer, Tamar: "From Zero to Hero: Masculinity in Jewish Nationalism", en Tamar Mayer (ed.): Gender Ironies of Nationalism. Sexing the Nation, Nueva York, Routledge, 2000, pp. 283-307.

Mayer, Tamar (ed.): Gender Ironies of Nationalism. Sexing the Nation, Nueva York, Routledge, 2000.

McClintock, Anne: Imperial Leather. Race, Gender and Sexuality in the Colonial Contest, Nueva York, Routledge, 1995.

Molina, Fernando: "La nación desde abajo. Nacionalización, individuo e identidad nacional", Ayer, 90 (2013), pp. 39-63.

Moreno, Raúl: "La nación de los sujetos: propuestas para una investigación de los fenómenos nacionales a comienzos de la época contemporánea", Rubrica Contemporanea, 6-11 (2017), pp. 5-23.

Mosse, George L.: Nationalism and Sexuality. Respectability and Abnormal Sexuality in Modern Europe, Nueva York, Howard Fretig, 1985.

Mosse, George L.: La imagen del hombre. La creación de la moderna masculinidad, Madrid, Talasa, 2001.

Nagel, Joan: "Masculinity and Nationalism: Gender and Sexuality in the Making of Nations", Ethnic and Racial Studies, 21-2 (1998), pp. 242-269.

Nash, Mary: "Masculinidades vacacionales y veraniegas: el Rodríguez y el donjuán en el turismo de masas", Rubrica Contemporanea, 7-13 (2018), pp. 23-39.

Patriarca, Silvana: “A Patriotic Emotion: Shame and the Risorgimento", en Silvana Patriarca y Lucy Riall (eds.): The Risorgimento Revisited. Nationalism and Culture in NineteenthCentury Italy, Nueva York, Palgrave Macmillan, 2012, pp. 134-151.

Peluffo, Anna y Sánchez Prado, Ignacio M. (eds.): Entre hombres: masculinidades del siglo XIX en América Latina, Madrid y Frankfurt, Iberoamericana-Vervuert, 2010.

Pitt-Rivers, Julian: Antropología del honor o Política de los sexos: ensayos de antropología mediterránea, Barcelona, Crítica, 1979.

Pocock, J. G. A.: El momento maquiavélico: el pensamiento político florentino y la tradición republicana atlántica, Madrid, Tecnos, 2002.

Puar, Jasbir K.: Ensamblajes terroristas. El homonacionalismo en tiempos queer, Barcelona, Bellaterra, 2017.

Reeser, Todd: Masculinities in Theory. An Introduction, Oxford, Willey-Blackwell, 2010.

Santamaría, Sara: "Una nación moderna. Masculinidades españolas postimperiales frente a Guinea Ecuatorial”, Stvdia Historica. Historia contemporánea, 38 (2020), en prensa. 
Schippers, Mimi: "Recovering the Feminine Other: Masculinity, Femininity, and Gender Hegemony", Theory and Society, 36-1 (2007), pp. 85-102.

Sewell Jr., William H.: Logics of History: Social Theory and Social Transformation, Chicago, University of Chicago Press, 2005.

Sierra, María: "Hombres arcaicos en tiempos modernos. La construcción romántica de la masculinidad gitana", Historia social, 93 (2019), pp. 51-65.

Sinha, Mrinalini: Colonial Masculinity. The 'manly Englishman'and the 'effeminate Bengali' in the late nineteenth century, Manchester, Manchester University Press, 1995.

Sinha, Mrinalini: "Giving Masculinity a History: Some Contributions from the Historiography of Colonial India", Gender \& History, 11-3 (1999), pp. 445-460.

Sinha, Mrinalini: "Nations in an Imperial Crucible", en Philippa Levine (ed.): Gender and Empire, Oxford, Oxford University Press, 2004, pp. 181-202.

Slootmaeckers, Koen: "Nationalism as Competing Masculinities: Homophobia as a Technology of Othering for Hetero- and Homonationalism”, Theory and Society, 48 (2019), pp. 239-265.

Sohn, Anne-Marie: “Sois un Homme!” La construction de la masculinité au XIXe siècle, París, Seuil, 2009.

Sohn, Anne-Marie: "Nation et apprentisage de la masculinité. L'exemple des jeunes Français aux XIXe siècle”, Mélanges de la Casa de Velázquez, 42-2 (2012), pp. 143-160.

Sommer, Doris: Foundational Fictions: the National Romances of Latin America, Berkeley, University of California Press, 1993.

Spear, Gary: "Shakespeare's Manly Parts: Masculinity and Effeminacy in Troilus and Cressida", Shakespeare Quarterly, 44-4 (1993), pp. 409-422.

Theveleit, Klaus: Males Fantasies, Minneapolis, University of Minnesota Press, 1987.

Torres, Gemma: "La nación viril. Imágenes masculinas de España en el africanismo reaccionario después de la derrota de Annual (1921-1927)", Ayer, 106 (2017), pp. 133158.

Torres, Gemma: La virilitat d'Espanya a l'África. Nació $i$ masculinitat al colonialisme al Marroc (1880-1927), Catarroja, Afers, 2020.

Torres, Gemma: "Emociones viriles y la experiencia de la nación imperial en las guerras del Rif (1909-1927)", Stvdia Historica. Historia Contemporánea, 38 (2020), en prensa.

Torres, Gemma (coord.): L'home espanyol davant dels seus altres: masculinitat, colonialitat i classe, Rubrica Contemporanea, 7-13 (2018).

Tosh, John: A Man's Place. Masculinity and the Middle-Class Home in Victorian England, Londres, Yale University Press, 1999.

Tosh, John: "Hegemonic Masculinity and the History of Gender", en Stefan Dudink, Karen Hagemann y John Tosh (eds.): Masculinities in Politics and War. Gendering Modern History, Manchester, Manchester University Press, 2008, pp. 41-58.

Vázquez García, Francisco y Cleminson, Richard: Los Invisibles: una historia de la homosexualidad en España, 1850-1939, Granada, Comares, 2011.

Waetjen, Thembisa: "The Limits of Gender Rhetoric for Nationalism: A Case Study from Southern Africa", Theory and Society, 30 (2001), pp. 121-152.

Wahrman, Dror: The Making of the Modern Self. Identity and Culture in Eighteenth-Century England, Londres, Yale University Press, 2006.

Wenk, Silke: "Gendered Representations of the Nation's Past and Future", en Ida Blom, Karen Hagemann y Catherine Hall (eds.): Gendered Nations. Nationalisms and gender order in the long nineteenth century, Nueva York, Berg, 2000, pp. 63-77. 
Wimmer, Andreas y Schiller, Nina Glick: "Methodological Nationalism and Beyond: Nation-State Building, Migration and the Social Sciences", Global Networks, 2-4 (2002), pp. 301-334.

Yuval-Davis, Nira: Gender \& Nation, Londres, Sage, 1997.

Zabalgoitia, Mauricio (ed.): Hombres en peligro: género, nación e imperio en la España de cambio de siglo (XIX-XX), Madrid, Iberoamericana-Vervuert, 2017. 
